\title{
Resenha
}

Livro: A Vida para o consumo: a transformação das pessoas em mercadoria, de Zygmunt Bauman. Rio de Janeiro: Jorge Zahar, 2008.

\section{A VIDA PARA O CONSUMO: SUJEITOS COMO MERCADORIA}

\author{
Marina Caminha ${ }^{1}$
}

Na parte final do livro A vida para o consumo, Bauman escreve:

\begin{abstract}
A busca por prazeres individuais articulada pelas mercadorias oferecidas hoje em dia, uma busca guiada e a todo tempo redirecionada e reorientada por campanhas publicitárias sucessivas, fornece o único substituto aceitável - na verdade, bastante necessitado e bem-vindo - para a edificante solidariedade dos colegas de trabalho e para o ardente calor humano de cuidar e ser cuidado pelos mais próximos e queridos, tanto no lar como na vizinhança (BAUMAN, 2008: 154).
\end{abstract}

Esse parágrafo pode ser encarado como a chave de leitura do livro, pois aponta como as relações humanas, a partir do que ele vai chamar de sociedade de consumidores, constituem-se. De um lado, a mercadoria como centro das práticas cotidianas. De outro, uma constante orientação para que o modelo de conduta seja sempre articulado através do ato de consumir.

Para Bauman, o adensamento do consumo como fenômeno que regulamenta as ações sociais, políticas e cotidianas é o que o torna peculiar nas sociedades contemporâneas. Se o mercado passa a ser o novo espaço modelador da vida, é através de suas leis que as relações em disputa pelo poder, identidade e inclusão/exclusão passam a ser reconfiguradas. Dentre elas, encontra-se a desregulamentação, a produção incessante de desejos materializados em produtos e, em conseqüência, o desperdício.

O autor vai dizer que o jogo do mercado é fabulado por três regras: a primeira, prediz que todo produto é vendável e visa ser consumido; a segunda, que esse consumo

\footnotetext{
${ }^{1}$ Aluna de Doutorado do Programa de Pós-Graduação em Comunicação da Universidade Federal Fluminense - UFF. Mestre em Comunicação pela mesma instituição. Email: marinacaminha@hotmail.com
} 
se vincula a satisfação de desejos; por fim, o valor a ser pago é dependente direto da confiabilidade da "promessa de satisfação” e "intensidade de desejos”. Nesse sentido, diz ele, "a sociedade dos consumidores se distingue por uma reconstrução das relações humanas a partir das relações entres os consumidores e os objetos de consumo” (Idem: 18 e 19).

Emerge, desse modo, um novo tipo de habitante - na verdade, o único possível -, capaz de atuar no campo das possibilidades pré-determinadas pelo mercado, e essa se torna a questão principal do livro: a conformação do sujeito em mercadoria. Na visão do autor, todas as relações só podem ser empreendidas a partir do consumo, não há nada fora deles:

A "subjetividade" do sujeito, e a maior parte daquilo que essa subjetividade possibilita ao sujeito atingir, concentra-se num esforço sem fim para ela própria se tornar, e permanecer, uma mercadoria vendável (Idem: 20).

Diante de uma sociedade de consumo excessivo, a necessidade de mobilidade e visibilidade é cada vez maior, deflagrando uma constante reformulação das identidades como formas de assegurar os princípios de inclusão/exclusão elaborados pelo mercado. Para Bauman, não existe um não-consumidor, mas sim um consumidor falho.

É nesse sentido que as estratégias de pertencimento empreendidas por esses sujeitos são cada vez mais ancoradas em uma intensa produção de notoriedade sobre si como lugar de significação. O que convém é se tornar vendável, portanto, visível, capaz de dar sustentação às intrigas que formulam a vida consumista. É por esse palco nervoso que as disputas se articulam, sendo aí percebidas, valoradas e distinguidas.

O mercado é uma instância central e as relações de inclusão e exclusão são determinadas pelas suas regras. Analisar o consumo significa, para o autor, o momento em que ele orienta, sustenta e redimensiona as mediações sociais. É entendido como cultura por que possui uma dimensão simbólica e pedagógica, atuando na “administração do espírito” (Idem: 73). Mary Douglas já ia por essa mesma linha de raciocínio ao afirmar que:

A teoria do consumo tem de ser uma teoria da cultura e uma teoria da vida social. Se a organização funciona suficientemente bem, pode dotar os objetos de valor; dizer de um objeto que ele está apto para o consumo é o mesmo que dizer que o objeto está apto para circular como marcador de conjuntos particulares de papéis sociais (DOUGLAS, 2006: 41). 
Para Bauman, a existência de uma cultura do consumo se formula na passagem de uma sociedade de produtores para uma de consumidores, sendo os marcos dessa transformação o início dos anos de $1980^{2}$, como foi sugerido por Gilles Lipovetsky $(2007)^{3}$. O que poderia, portanto, ser entendido como mudança nos padrões de comportamentos humanos, apontando para um novo espírito do tempo, vai ser analisado pelo autor a partir de três perspectivas: a percepção de uma nova maneira de experimentar o tempo; a forma vivenciada da felicidade/afetividade; e a relação Estado versus individualismo.

Essas perspectivas, por sua vez, são imbricadas, uma tornando-se conseqüência da outra e vice-versa, procedimento que recoloca o mercado como instância central. Em paralelo a essa análise, o autor disserta sobre a formação de uma "indústria de remoção do lixo”, viés pelo qual entrelaça as três características e confirma sua premissa inicial do sujeito-mercadoria. É preciso ressaltar ainda que a metodologia aplicada por Bauman leva em conta o conceito de tipo ideal proposto por Max Webber.

Como sugere Julien Freund, o tipo ideal é uma forma metodológica para compreender as relações entre permanências e rupturas de um modo de ação, buscando na exacerbação da singularidade dos fenômenos analisados um recorte para tornar a 'realidade social' um objeto empírico:

Ele (o tipo ideal) consiste em uma representação ideal e conseqüente de uma totalidade histórica singular, obtida por meio de racionalização utópica e de acentuação unilateral dos traços característicos e originais, para dar uma significação coerente e rigorosa o que parece

\footnotetext{
${ }^{2}$ Mantenho aqui a divisão estabelecida por Gilles Lipovetsky por percebê-la relacionada com a perspectiva de Bauman, ainda que este não tenha citado o primeiro. Bauman, no final do seu livro, aponta a atuação Margaret Thatcher como primeira-ministra do Reino Unido (entre 1979 e 1990) como paradigmática de um processo econômico e político que transformou a retórica do capitalismo e com isso, a do consumo. Entre as suas principais ações, constava a privatização das empresas estatais, condicionando o deslocamento da responsabilidade da organização da vida pública, antes designada pelo estado para o mercado.

${ }^{3}$ Para Lipovetsky o capitalismo do consumo se dividiria em três fases: a primeira, entre os anos de 1880 e a segunda guerra mundial, que se constituiu pela transformação dos mercados de consumo visando uma produção em larga escala, denominado por ele como "mercados de massa". A segunda, entre os anos de 1950 e 1980, foi marcada pela regulamentação e racionalização da economia através do modelo fordista, considerada pelo autor como a fase de "superabundância" e ostentação na aquisição de bens duráveis. A última, iniciada a partir dos anos de 1980, é marcada pela predominância de um turboconsumo no qual o que está em foco é o fetiche da subjetividade, transformando o consumismo em um modo central pelo qual as experiências são adquiridas. Nesse sentido, o autor atenta para o adensamento de um consumo hedonístico e juvenil, em que o prazer momentâneo torna-se a principal estratégia de venda, recondicionando, em conseqüência, a experiência de viver o tempo. Cf: LIPOVETSKY, Gilles. A felicidade paradoxal. São Paulo: Cia. das Letras, 2007.
} 
como confuso e caótico em nossa experiência puramente existencial (FREUND, 2006: 50).

Bauman, ao propor uma análise a partir desse conceito, deixa claro seu ponto de partida: analisar elementos que possam gerar uma definição do que ele nomeia como sociedade dos consumidores, ainda que aponte para um ponto de vista e esmaeça as contradições existentes nos fluxos das experiências vividas.

\section{Três singularidades: o tempo, a afetividade e a relação Estado $x$ indivíduo.}

$\mathrm{Na}$ sociedade de produtores, o ethos que alinhavava todo um modelo de produção era estruturado na perspectiva de que adquirir bens assegurava uma maior comodidade e status social. O projeto capitalista daquele momento investia no disciplinamento, na organização e na regulação do corpo trabalhador. Apostava na produção de desejos sempre orientados para o futuro, conclamando o consumidor a ter acesso, via aquisição de produtos, a uma vida "resistente ao tempo" e segura (BAUMAN, Op. Cit.: 42).

Para o autor, o que se torna singular na cultura do consumo é a inversão dos valores que nortearam o projeto capitalista numa sociedade de produtos; atualmente, é o desejo humano de estabilidade o seu principal fator de risco. Bauman vai dizer que uma das singularidades desse tipo de sociedade é a constante promoção de novas necessidades, projetando uma incessante remodelação dos desejos através de novos e melhores produtos. Assim, o imaginário que configura essa sociedade é a descrença na orientação para o futuro, retirando "do adiamento da satisfação seu antigo sentido de prudência, circunspecção e, acima de tudo, razoabilidade”. Portanto, o contemporâneo passa a ser entendido pelo autor como fase líquida da modernidade, na qual as formas de satisfação são sempre momentâneas. É o tempo presente que orienta a arquitetura comportamental dos consumidores (Idem: 45).

A capacidade de ressignificação do tempo é o fator que mantém um equilíbrio no sistema e atravessa as práticas diárias, atualizando as maneiras de sentir e de conduzir o afeto. Na mesma medida em que conclama o consumo desenfreado, eleva a produção do desperdício, o que para Bauman, reflete uma cultura da "obsolescência embutida” (Idem: 45). 
O tempo deixa de ser linear e orientado para o futuro para se tornar "pontilhista", ou seja, a autonomia do presente perante o passado e o futuro, legitimando o momento sempre como um novo recomeço, "no qual surpresas, golpes inesperados de boa sorte e oportunidades imprevistas podem aparecer a qualquer instante”. Assim, a noção de segurança, estabilidade e pertencimento passa também a ser construída sob o signo do efêmero, na busca desenfreada por “descartar e substituir” através das novas oportunidades da próxima semana (Idem: 47 e 50):

A síndrome consumista coloca as precauções contra a possibilidade de as coisas abusarem da hospitalidade no lugar da técnica de segurá-las de perto, e da vinculação e do comprometimento de longo prazo. Também encurta radicalmente a expectativa de vida do desejo e a distância temporal entre este e sua satisfação, assim como entre a satisfação e o depósito de lixo (Idem: 111).

Desse modo, convida o consumidor a uma alegria e a um rejuvenescimento constantes, geradores de sucessivas tentativas de novos acertos e erros. Estar atado a esse mundo, para Bauman, é “sentir a infinidade de conexão, mas não estar engatado em coisa alguma”, resultando numa paradoxal relação entre satisfação dos desejos e “aflição” (Idem: 58). Desse modo, a relação entre as formas como somos afetados pela cultura consumista e criamos afetos só poderia ser interpretada pela lógica de gerenciamento elaborada pelos mercados de consumo. $\mathrm{O}$ autor recorre à promessa de felicidade enraizada no discurso líquido moderno e analisa se esse sentimento é, de fato, vivenciado pelos sujeitos consumidores no próprio processo que é tomado como valor nesse tipo de sociedade.

Para ele, o que vigora como valor é justamente o motivo por meio do qual tal promessa não se confirma, já que o fascínio perdura apenas na ansiedade pela satisfação e, portanto, para cada vontade adquirida, implica a criação de uma nova. Desse modo, a formulação do desejo se relaciona a uma economia de mercado que se sustenta pela promoção, desvalorização e criação de novos anseios. A obsolescência ilimitada, conforme o autor, constitui-se como um dos principais pilares da cultura do consumo e passa a prescrever um hábito:

E assim ocorre, desde que o impulso para buscar soluções de problemas e alívio par as dores e ansiedades nas lojas, e apenas nelas, continue sendo um aspecto do comportamento não apenas destinado, mas encorajado com avidez, a se condensar num hábito ou estratégia sem alternativa aparente (Idem: 64). 
Por isso, a idéia de felicidade só pode ser entendida por Bauman como um lugar ilusório em que o vasto empreendimento de novas promessas esmaece o excesso de decepções, fazendo com que a crença nessa busca não seja perdida e permaneça reatualizando a cultura consumista. Assim, o consumo se configura como uma atividade solitária, sem "vínculos duradouros”, substituindo o que era interpretado como valor (o investimento no futuro) nas sociedades de produtores, para o gasto rápido nas sociedades dos consumidores.

Para chegar a essa conclusão, Bauman faz uma revisão histórica da maneira como o processo civilizador ${ }^{4}$ desestruturou os modos de organização baseado em leis geridas pelas leis comunais na sociedade tradicional. Ele argumenta que, no processo civilizador - coerção sobre o corpo do indivíduo (Freud) - a noção de comunidade só se tornou questão no momento em que entrou em crise, fazendo, então, surgir a idéia do Estado-nação e do indivíduo.

Foi sob a égide do patriotismo que a "descoberta” da liberdade do indivíduo foi utilizada em função “da supressão de escolhas (individuais) consideradas prejudiciais à nova totalidade: a comunidade Estado-nação”, naturalizando e legitimando as estratégias de dominação presentes na organização das cidades modernas (Idem: 96).

A condição pós-moderna, para Bauman, deflagra uma outra vertente do processo civilizador: ao transformar a necessidade de liberdade em imaginário gera uma maneira menos conflituosa de ancorar a hegemonia do mercado sobre o indivíduo, já que se configura pela obrigatoriedade, como vocação/comprometimento, de escolha como se fosse de fato uma possibilidade de autonomia do sujeito:

A garantia, com freqüência repetida, de que este é um país livre significa: é sua responsabilidade o tipo de vida que deseja levar, como resolve vivê-la e os tipos de escolha que você faz para que seu projeto se concretize; culpa a si mesmo, e a ninguém mais, se tudo isso não resultar na felicidade que você esperava (Idem: 113).

Nesse sentido, o projeto impresso pela cultura consumista legalizou uma maneira de atuação alternativa às políticas do Estado-nação nas sociedades de produtores. Garantiu uma maior liberdade para o indivíduo a partir do enfraquecimento da soberania do estado, que agora aparece como executor-facilitador das leis impostas

\footnotetext{
4 Para Bauman, o conceito de processo civilizador proposto por Norbert Elias se constitui pela “internalização das restrições externas e suas pressões", através de poderes panópticos no processo de formatação dos sujeitos modernos (Op. Cit.: 96).
} 
pelo mercado. Não é mais a obrigatoriedade no cumprimento das regras o que se configura como retórica no mundo líquido moderno, mas sim, o gerenciamento do divertimento/prazer a serviço de uma constante busca pela felicidade: "um patriotenimento, uma folia procurada com avidez e eminentemente festiva” (Idem: 98).

\section{Considerações finais.}

No início do terceiro capítulo, o autor aponta a maneira como uma campanha publicitária justifica a compra de um produto a partir da legenda esteja à frente do seu tempo. Para Bauman, essa frase pode ser encarada como uma metáfora sobre a cultura do consumo, pois indica, primeiro, que as “marcas de pertencimento" na sociedade líquido-moderna são direcionadas a construção de estilos de vida, via bens de consumo; segundo, significa que tais bens são desvalorizados muito rapidamente e, portanto, a única possibilidade de pertencimento/segurança está em uma constante mobilidade dos sujeitos para se desfazerem de seus objetos e escolhas por outros. É sempre necessário subjugar o tempo, como uma espécie de reconhecimento das regras do jogo, já que este se constitui a partir de uma sucessão de novos presentes.

Por fim, é o próprio indivíduo que é convocado a escolher. A cultura do consumo, portanto, se constitui pela "revogação dos valores vinculados respectivamente à duração e a efemeridade” como “marcas de pertença” em que o sinônimo de liberdade se constitui pelo de tomar pra si a responsabilidade de escolha, refletindo um "estado de emergência” em que a probabilidade de resposta só pode ser configurada na intensidade como se vive o presente (Idem: 108, 111 e 120).

Assim, emerge um estado de aflição, simbolizado pelo sentimento de inadequação diante da eterna tentativa de domínio do tempo, acarretando na formação de um imaginário que relaciona o uso e o descarte como essenciais para a idéia de movimento constante:

A vida do consumidor, a vida do consumo não se refere à aquisição e posse. Tampouco tem a ver com se livrar do que foi adquirido anteontem e exibido com orgulho no dia seguinte. Refere-se, em vez disso, principalmente e acima de tudo, a estar em movimento (Idem: 126).

Bauman formulou uma análise sobre a cultura do consumo a partir da voz dominante, enumerando as estratégias de dominação revertidas em lugares de ordenação, construção de costumes e, portanto, visão de mundo. É nesse sentido que a 
mercadoria figura como elemento mitológico desse espaço social. Para o autor, a nova retórica capitalista impõe lógicas de inclusão "muito mais estritas, duras e inflexíveis do que na sociedade dos produtores” e, assim, os sujeitos que nela habita só poderão fazer parte quando eles mesmos se interpretam como produtos vendáveis, reconhecendo que o consumo é hoje o único meio pelo qual os critérios de legitimação e de distinção são tomados como valores (idem: 64).

A meu ver, se o centro da teoria de Bauman é a liquidez no mundo moderno, uma das maneiras que temos de complexificar seu pensamento diante do que interpretamos como cultura do consumo é a aplicação de seus conceitos em objetos empíricos que nos obrigam a olhar para o lugar do consumidor.

Dessa forma, um caminho de aplicação que evidencia esse diálogo pode ser encontrado a partir do conceito de táticas proferido por Michel de Certeau (2005). Situado no lugar da recepção, as táticas são concebidas pelas mil maneiras de “fazer com” reveladas nas práticas do cotidiano, ou seja, nos modos de ação.

Faz-se necessário para Certeau o surgimento de uma categoria capaz de responder de que maneira os meios populares fazem usos das culturas difundidas. Analisar esses modos é um começo para desfazer o mal entendido que transforma o lugar da recepção em um ambiente passivo.

Para o autor, dentro desse trânsito que organiza o contexto cultural das sociedades modernas, ratificado pela lógica da comercialização de bens, há sempre um modo de fazer, e é nesse que se materializam as criações astuciosas dos consumidores, capaz de dotar de novas significações esses produtos em prol do seu próprio favorecimento.

As táticas tornam-se lugar de escape: elas não propõem uma mudança na ordem, porém, tiram dela proveito e, por conseguinte, modificam o seu sentido. É uma articulação que se capta no momento do uso, na arte invisível desses receptores ao converterem as estratégias em benefícios próprios, situando-se no cotidiano, na linguagem localizada: “são frases imprevisíveis num lugar ordenado pelas técnicas organizadoras dos sistemas” (Idem: 97).

Assim, as táticas situam-se em contraposição às estratégias, que se definem pela ordem através da qual se consolidam as instituições nacionais, tais como a política, a economia e a cultura oficial. A estratégia é “algo próprio a ser base de onde se podem 
gerir as relações com uma exterioridade de alvos ou ameaças” e se efetua nas relações de força de uma organização, cultural, por exemplo, que exige pra si um domínio isolado do poder. “É a vitória do lugar sobre o tempo” (Idem: 99).

Acredito que, dessa maneira, possamos ter uma visão um pouco mais complexa de um processo cultural, pois, ainda que a teoria de Bauman seja importante como desmascaramento de um modo de organização social, a forma como "nós" sujeitos fazemos usos não só dos produtos, mas também do que se arquiteta como sentido no mundo do consumo, permitem aprofundar outros modos de organização, indicando que as disputas por significação é parte constituinte do arenoso terreno da cultura.

\section{Referências bibliográficas}

BAUMAN, Zygmunt. Vida para o consumo: a transformação das pessoas em mercadoria. Rio de Janeiro: Jorge Zahar, 2008.

CERTEAU. Michel de. A invenção do cotidiano: 1. artes de fazer. Petrópolis: Vozes, 2005.

DOUGLAS, Mary. O mundo dos bens: para uma antropologia do consumo. Rio de Janeiro: UFRJ, 2006.

FREUND, Julien. Sociologia de Max Webber. Rio de Janeiro: Forense Universitária, 2006.

LIPOVETSKY, Gilles. A felicidade paradoxal. São Paulo: Cia. das Letras, 2007. 